\title{
VII
}

\section{OS SURDOS E A (IN)ACESSIBILIDADE AOS MUSEUS EM UBERABA/MG: QUESTÃO CULTURAL OU LINGUÍSTICA?*}

Ariany Palhares de Oliveira Borges Vicente Mayara Laura Rocha Rossi Martins

\section{Introdução}

Este capítulo traz uma breve apresentação sobre o acesso de surdos a espaços educativos não formais e aponta desafios e possibilidades para melhorar ou viabilizar o acesso a estes espaços pela comunidade Surda uberabense. Há muito se problematiza a questão da inclusão de pessoas Surdas no contexto educacional, porém temos refletido como esta inclusão vem sendo realizada não apenas neste contexto, mas em todos os ambientes frequentados socialmente por Surdos.

É sabido que o primeiro meio social ao qual o ser humano é exposto é a própria família e que, em se tratando de Surdos, filhos de pais ouvintes, em nossa prática cotidiana como tradutoras-intérpretes de Língua Brasileira de Sinais (Libras), comumente nos deparamos com situações nas quais os pais não se comunicam com seus filhos por meio da Libras, mas por meio de sinais "caseiros" ou, ainda, combinados/condicionados, ou seja, o diálogo entre pais e filhos acaba se tornando restrito a ações diárias como comer, tomar banho e realizar atividades corriqueiras.

Após o contato familiar o Surdo é inserido no contexto da educação escolar, no qual é apresentado abruptamente a um universo bicultural e é exatamente neste momento em que a criança surda come-

*DOI - 10.29388/978-65-86678-24-6-0-f.135-156 
ça a delinear sua identidade. Desta forma, o Surdo que é inserido em uma escola para Surdos e mantém contato com outras crianças na mesma condição, usuárias da língua de sinais, e ainda tem como modelo linguístico e cultural um professor Surdo ou um professor ouvinte, mas fluente em Libras, estará imerso em um ambiente cultural muito propício para o seu desenvolvimento cognitivo, linguístico, cultural e, posteriormente, social.

Por outro lado, há crianças Surdas as quais os pais optam por inseri-las em escolas regulares sem a presença, na maioria dos casos, de outras crianças Surdas e também sem a participação de professores usuários da língua de sinais. Neste caso, a criança Surda estará exposta a um ambiente cultural que não lhe é natural, por tratar-se de um espaço que oferece o tempo todo estímulos orais-auditivos.

Mas qual o motivo de discorrermos sobre este assunto? Pelo fato de que os Surdos não estão expostos somente à família e à escola. Serão inseridos no mundo do trabalho, constituirão suas famílias e também passarão a frequentar ambientes comuns a toda sociedade.

E é justamente sobre estes ambientes, mais especificamente sobre os Museus, que passaremos a discorrer nas próximas linhas. Ainda na fase de escolarização é comum vermos grupos de estudantes visitando espaços externos à escola, como zoológicos, parques e museus, acompanhados em geral por professores de Geografia, História ou Ciências da Natureza; não obstante, os Surdos também frequentam estes espaços acompanhando a turma em que estão matriculados.

Estes espaços dificilmente são frequentados espontaneamente por Surdos (ou seja, quando não se trata de visita escolar) e, quando o são, é comum que a visitação tenha um cunho voltado exclusivamente ao entretenimento e não à possibilidade de construção de novos conceitos e conhecimentos.

Assim, nosso objetivo é refletir acerca de como se dá a inclusão de Surdos em três museus na cidade de Uberaba/MG, tendo em vista possibilitar a ele(a) um espaço não apenas de acolhida e lazer, como também um universo visual repleto de conceitos e valores culturais. 


\section{Museus em Uberaba: quais são e como recebem os Surdos?}

Antes de darmos início às discussões sobre os Museus em Uberaba/MG, faremos um breve apanhado sobre a educação em espaços escolares e não escolares e, neste sentido, Gaspar (2002) ressalta que há a interação da educação formal com a educação não formal, ou seja, a aprendizagem de um novo conceito é um processo de desenvolvimento cognitivo longo, cuja construção apenas começa na ocasião em que é ensinado.

No ambiente escolar os Surdos estão o tempo todo expostos a materiais didáticos, entretanto observamos que estes não são condizentes com sua realidade por apresentarem o conteúdo dentro de uma cultura ouvinte, pautada na escrita em Língua Portuguesa (LP). Neste sentido, apontamos que os Museus são recursos válidos para a educação de Surdos por se tratarem de ricas fontes e oportunidades para que os Surdos construam novos conhecimentos, por apresentarem de forma visual-espacial os artefatos. Por outro lado, mesmo dispondo de vários recursos, percebe-se que estes são pouco ou quase nada explorados por Surdos, que por sua vez não encontram objetivo em realizar uma visita a espaços os quais, comumente, não oferecem acessibilidade comunicacional, por meio da Libras. De acordo com Salles, Faustich e Carvalho (2004, p. 47):

Recomenda-se que a educação dos surdos seja efetivada em língua de sinais, independentemente dos espaços em que o processo se desenvolva. Assim, paralelamente às disciplinas curriculares, faz-se necessário o ensino de língua portuguesa como segunda língua, com a utilização de materiais e métodos específicos no atendimento às necessidades educacionais do surdo. Nesse processo, cabe ainda considerar que os surdos se inserem na cultura nacional, o que implica que o ensino da língua portuguesa deve contemplar temas que contribuem para a afirmação e ampliação das referências culturais que os identificam como cidadãos brasileiros. 
Falk (2002) destaca que a escola não é o único espaço que privilegia a aprendizagem científica, salientando que são diversos os locais e meios de acesso ao conhecimento científico. Marandino (2008) define a educação fora da escola como qualquer atividade organizada externamente ao sistema formal, operando separadamente ou como parte de uma atividade ampla, que possui objetivos de aprendizagem.

Seguindo esta linha, a não frequência de Surdos a estes espaços nos têm chamado a atenção, uma vez que museus são espaços com forte apelo visual para a divulgação de seu acervo e, em geral, contam com materiais manipulativos. Assim, o que falta para que sejam mais bem explorados por este público, em especial?

Em Uberaba/MG queremos focalizar a realidade de três espaços, a saber: Museu de Arte Sacra, localizado à Praça Manoel Terra, s/ n; Museu dos Dinossauros, que fica às margens da BR 262, km 784, Bairro Rural de Peirópolis, e Museu do Zebu, localizado dentro do Parque de Exposições Fernando Costa, mais especificamente na Praça Vicentino Rodrigues da Cunha, 110 - Bloco 22. Depois da escolha dos três espaços elencamos perguntas direcionadas aos responsáveis pelos museus.

Vocês recebem visitas de Surdos em suas dependências?

O Museu conta com um profissional tradutor/intérprete de Libras?

Já receberam Escolas com estudantes Surdos?

O museu é aberto a este público?

Vocês se sentem preparados para receber este público?

Como poderiam receber Surdos?

Após contato por telefone, em uma conversa informal com os três museus, tivemos acesso às informações sobre as quais passaremos a discorrer:

O Museu de Arte Sacra informou que não se recorda de mediações de visitas realizadas pelo público Surdo e que não possui intérpretes disponíveis para recebê-los, o que é reforçado pelo fato de não haver registro de visitas escolares realizadas com este público. Fomos in- 
formados de que o espaço está aberto para recebê-los, mas que não se sentem preparados pela falta de conhecimento da língua e também pela ausência de um intérprete.

Em conversa com a secretária que trabalha no Museu do Zebu há quase dois anos, esta também afirmou que não se recorda de visita realizada por Surdos. Afirmou, ainda, que, desde a sua admissão, o espaço não possui intérprete e que desconhece informação sobre visitas de escolas que contassem com estudantes Surdos em seu corpo discente. Sobre estarem preparados para o trabalho com este público, ela afirma que o espaço é repleto de artefatos visuais e que acredita que este fator pode auxiliar o público Surdo que desejar conhecer/visitar o espaço e que poderiam, sim, recebê-los, mas que precisaria verificar a possibilidade de contar com um intérprete para mediar a visita.

O Museu dos Dinossauros foi o único a informar que recebe Surdos em suas dependências, porém não possui um intérprete à disposição da comunidade Surda. Escolas com estudantes Surdos já visitaram o espaço e o Museu é aberto para recebê-los. Quando perguntados se se sentem preparados, declararam que o espaço possui parceria com estudantes da Universidade Federal do Triângulo Mineiro (UFTM) e que, em havendo necessidade, estes deslocam-se voluntariamente ao Museu para atender ao grupo e que os universitários, por terem Libras em sua matriz curricular, conseguem ao menos receber de forma mais humanizada este público. Relataram, ainda, que se tivessem a oportunidade de ter um profissional habilitado no espaço, provavelmente este fator atrairia mais a comunidade Surda para o Museu.

O contato realizado com os espaços não nos deixou dúvidas a respeito da urgência de mais pesquisas e discussões acerca de como tornar estes espaços acessíveis à comunidade Surda. Sabemos da falta de investimentos e recursos destinados a essa área; todavia necessário se faz que a inclusão e suas discussões ultrapassem os muros da escola, dando autonomia e o direito de ir e vir a esta comunidade. 


\section{Inclusão de Surdos e a Legislação}

A Libras, como instrumento para que a real adaptação em museus aconteça, vem sendo difundida com o objetivo de que pessoas, em qualquer espaço educativo, inclusive o dos museus, possa receber os Surdos com igualdade de direitos. Esta, desde 2002, foi reconhecida e oficializada como segunda Língua do Brasil, por força da Lei $n^{\circ}$. 10.436/2002 (BRASIL, 2002). Após este fato os Surdos que já a utiliza vam em diferentes espaços começaram a cobrar por seus direitos linguísticos de se apresentarem por ela e de receberem a informação também por meio dela.

No contexto atual, a comunidade Surda vem gradativamente se reconhecendo como participante de todo o processo histórico, social e político dentro de uma sociedade ainda excludente. Quando o assunto é acessibilidade, hoje uma das conquistas é a Lei $\mathrm{n}^{\circ}$. 10.098/00 (BRASIL, 2000) que defende os direitos de pessoas com deficiência; nela é possível destacar o excerto a seguir: “[...] barreiras nas comunicações: qualquer entrave ou obstáculo que dificulte ou impossibilite a expressão ou o recebimento de mensagens por intermédio dos meios ou sistemas de comunicação, sejam ou não de massa [...]" mas, apesar do reconhecimento dessas pessoas perante a lei, os museus vêm priorizando adaptações para receber cadeirantes e muletantes.

Observa-se que em espaços museológicos ainda são restritas as adequações, seja elas de natureza linguística, física e atitudinal para a inclusão de Surdos nesses lugares. Deste modo essa conquista se somou a outras mais atuais, que sempre passaram pelo campo da legislação. Nos últimos anos não foram poucas as leis e diretrizes que buscaram regulamentar aspectos da língua de sinais para propagar seu o uso e garantir direitos à comunidade Surda:

- Lei 4.304/04: determina o uso de recursos visuais e legendas nas propagandas oficiais do governo;

- Decreto 5626/05: organiza a implementação da Lei 10.436/2002; 
- Decreto 11.796/08: institui o Dia Nacional do Surdo, comemorado em 26 de Setembro, considerado o mês dos Surdos;

- Lei 12.319/10: regulamenta a profissão de Tradutor e Intérprete da Língua Brasileira de Sinais - Libras;

- Lei 13.146/15: Lei Brasileira de Inclusão (ou Estatuto da Pessoa com Deficiência), que trata da acessibilidade em áreas como educação, saúde, lazer, cultura, trabalho etc.;

- Resolução 667/16: a Agência Nacional de Telecomunicações (Anatel) publica regras para o atendimento das pessoas com deficiência por parte das empresas de telecomunicações.

Para que seja problematizada a entrada de Surdos na sociedade, é necessário remetermo-nos à compreensão da Surdez como diferença a qual, por definição, é concebida por representações em matizes de significações linguísticas, políticas e, principalmente, culturais. Tal premissa tem sido fundamentada na concepção da deficiência enquanto fenômeno histórico-social. Seguindo este pensamento, urge a necessidade de conscientização e informação para que a sociedade não perceba o Surdo como um sujeito deficiente ou, ainda, incapaz de realizar atividades ou de iniciar seus estudos em determinadas áreas, restringindo seus objetivos e abortando, muitas vezes, seus sonhos. Cada vez mais os Surdos têm se apropriado de novos conhecimentos e buscado outros espaços de atuação, o que demonstra empoderamento frente as políticas e à sociedade brasileira.

Com base nos estudos de Gesser, Nurenberg e Toneli (2013) pode-se afirmar que, para além das funções de funcionamento anátomo-fisiológico diferenciado da maioria das pessoas que se encontram na condição de Surdez, o contexto tem sido mais ou menos restritivo ao seu desenvolvimento para uma vida independente. Tais restrições remetem às barreiras presentes na sociedade em diferentes âmbitos, particularmente arquitetônico, metodológico, atitudinal, digital e, também, comunicacional.

Com a oficialização da Libras como língua natural do Surdo, inicia-se a construção de sua identidade, dentro de um universo cultural diferenciado linguisticamente. Até então as representações sobre a 
Surdez e o Surdo ainda são marcadas pelo discurso da deficiência. O Surdo é identificado pela falta, pela incapacidade e reconhecido como surdo-mudo e/ou deficiente auditivo: "a identidade do surdo, aqui, era atribuída socialmente mais pela inexistência da fala do que pelo déficit de audição" (FERREIRA, 2003, p. 23). Dentro deste discurso, é comum nos depararmos com situações que buscam pela "normalização" da pessoa Surda. Assim sendo, é possível identificarmos grandes avanços e conquistas, não obstante deve-se continuar lutando por uma sociedade igualitária, faz-se necessário haver empenho para que as barreiras comunicativas se dissolvam cada vez mais e que seja possível viver em um mundo com as mesmas oportunidades, no qual a inclusão aconteça efetivamente e não superficialmente.

Para que o processo aconteça de forma mais natural, é incontestável a atuação do profissional Tradutor-Intérprete de Libras, entretanto percebe-se que tão somente a presença deste profissional não é suficiente. Ao se refletir sobre a constituição da história desta profissão no Brasil visualiza-se, consultando bibliografia da área (QUADROS, 2004; MARTINS, 2009; SANTOS, 2013), que a atividade é reconhecida recentemente tanto no Brasil quanto no mundo, tendo início no contexto das ações de inclusão de Surdos nas instituições religiosas em diferentes países. Dentro do atual contexto, observa-se a crescente participação deste profissional em diferentes espaços, que até então eram mais comumente vistos em ambientes escolares. Contudo, a profissão recentemente reconhecida no Brasil, de acordo com o panorama legal acima trazido, se torna mais forte, entre outros elementos, pelos movimentos sociais da comunidade surda.

Com base em pesquisas realizadas no acervo histórico do Instituto Nacional de Educação de Surdos (INES), inicialmente denominado Imperial Instituto para Surdos-Mudos, inaugurado no Rio de Janeiro no ano de 1857, Rocha (2016) aponta em documentos datados de 1908 a tradução já era realizada, assim a "atuação desse profissional no campo da surdez data de mais de um século" (ROCHA, 2016, p. 247). Em relação à formação do profissional tradutor e intérprete, 
Nascimento (2016) mostra que, diferentemente de circunstâncias do intérprete de língua oral que surge em um contexto de diplomacia em situação de reconhecimento social e com evidência no contexto internacional, o intérprete de língua de sinais passa a ter visibilidade profissional a partir da necessidade de se garantir os direitos da comunidade surda no contexto educacional.

A literatura da área aponta que a participação dos tradutoresintérpretes teve início no âmbito religioso, espaço este responsável pelo reconhecimento da surdez como particularidade étnico-linguística, sendo também um espaço de experiências de formação de seus intérpretes, que passaram a atuar em diferentes esferas sociais que transcendem os muros das igrejas (SILVA, 2011). Esta realidade, até bem pouco tempo atrás, ainda se apresentava como uma fato e podemos dizer que foi graças ao contexto religioso que este profissional passou a se destacar também no ambiente escolar formal, todavia vivenciamos um momento de ampliação do papel deste profissional, haja visto a crescente participação deste em contextos jurídicos, políticos e midiáticos.

Esses movimentos foram essenciais para que chegássemos na atual conjuntura, com língua oficializada e também o reconhecimento e profissionalização do tradutor e intérprete de Libras. A língua de sinais não se apresenta apenas como língua utilizada na comunidade Surda, mas também como instrumento de trabalho do tradutor e intérprete, e a garantia de seu uso e difusão pelos direitos dos Surdos amplia as possibilidades de atuação desse profissional na efetivação das ações de inclusão do grupo social que faz uso desse meio de comunicação e expressão. Assim, destaca-se a importância de formação inicial e continuada para este profissional, uma vez que é de extrema responsabilidade o trabalho que desenvolverá, tanto no campo da tradução quanto na interpretação.

A partir das lutas e dos movimentos realizados pela comunidade Surda nacional, percebemos uma crescente transformação marcada por desafios e conquistas para os usuários da língua de sinais, desta- 
cando-se que: “[...] o movimento social Surdo iniciou uma ampla mobilização para chamar a atenção dos governos federal, estadual e municipal a favor do reconhecimento da Libras e da educação bilíngue para Surdos" (ZOVICO; SILVA, 2013, p. 128). Esses movimentos são organizados a partir de instituições representativas dos surdos e uma das entidades que apoiam a comunidade é a Federação Nacional da Educação e Integração de Surdos (Feneis), que não mediu esforços para que essas conquistas fossem idealizadas e efetivadas.

Em Uberaba, faz-se necessário destacar que várias ações também foram planejadas e conquistadas, como o caso de uma escola para crianças surdas e também uma escola de ensino regular inclusiva a qual, a partir dos primeiros surdos matriculados, sempre lutou pela presença de intérpretes de Libras como forma de garantir acessibilidade comunicacional no Ensino Fundamental II e Ensino Médio. Neste contexto, parte dos Surdos frequentava a escola com atendimento educacional especializado na Educação Infantil e anos iniciais do Ensino Fundamental e, posteriormente, seguiam para a segunda fase de seus estudos nesta escola inclusiva. Ressalta-se que até hoje esta parceria vem acontecendo e que mais uma conquista foi realizada nos últimos anos, com a implantação de um Centro de Capacitação de Profissionais da Educação e de Atendimento às Pessoas com Surdez (CAS), espaço este no qual os Surdos têm a possibilidade de interagir e conviver com a comunidade Surda local e usufruir de sua língua e cultura.

\section{Museu versus Cultura Surda e seus artefatos}

A comunidade Surda tem constantemente lutado por seus direitos e, principalmente, por sua cultura que se processa por meio de experiências visuais, da utilização e divulgação da Libras, de intérpretes presentes em diversos ambientes, do respeito às identidades Surdas e de uma metodologia de ensino diferenciada que de fato contemple o aprendizado da pessoa Surda, do reconhecimento do Povo Surdo e de sua Comunidade Surda. 
A Libras é a língua utilizada pela comunidade Surda, pois é por meio dela que o Surdo consegue perceber o mundo à sua volta, consegue atribuir significado e participar ativamente de movimentos sociais e educacionais. Strobel (2015, p. 53) define a Libras como:

[...] Uma das principais marcas da identidade de um povo surdo, pois é uma das peculiaridades da cultura surda, é uma forma de comunicação que capta as experiências visuais dos sujeitos Surdos, sendo que é esta língua que vai levar o surdo a transmitir e proporcionar-lhe a aquisição de conhecimento universal.

De acordo com a autora, percebemos que principalmente a comunicação da pessoa Surda deve ter como base a Libras, não só em espaços escolares, mas também nos espaços não escolares, destacando o museu como objeto de discurso neste contexto. Dentro deste espaço o ideal seria que o Surdo tivesse a Libras como língua base para a interação com os mediadores culturais presentes nesses espaços, que são profissionais dotados de um amplo conhecimento do acervo e das questões que o cercam. O mediador está presente para auxiliar o público a fruir e interpretar a exposição, de acordo com as bases de conhecimento e imaginação próprios, sem ter de recorrer a narrativas pré-determinadas pela instituição. Assim sendo, questiona-se o motivo pelo qual não compartilhar tais informações por meio da Libras na comunidade Surda.

Outro questionamento surge quando pensamos na possibilidade de trazer as novas tecnologias para dentro destes espaços, objetivando maior interação e assimilação das informações repassadas no museu. As adequações dos espaços deveriam ser uma premissa básica nos espaços educativos formais e não formais, principalmente por estarmos vivenciando uma fase dita inclusiva. Incluir de fato não se restringe ao fato de abrir as portas do museu para a comunidade surda, mas sim de oportunizar acesso ao conhecimento.

Ressaltamos que o Surdo se utiliza da comunicação em Libras para contar suas histórias, compartilhar informações, experiências, vi- 
vências e que, em havendo a possibilidade de registrar esses fatos, trata-se de uma forma de manter viva a história e a divulgação da língua. Novamente há de se pensar, neste caso, como as informações divulgadas nestes espaços seriam repassadas dentro da comunidade surda, posto que estas foram transmitidas o tempo todo em Língua Portuguesa a qual, por sua vez, se enquadra em uma modalidade oralauditiva, enquanto que a Libras é visual-espacial e considerada língua natural para a pessoa Surda. Será que a informação divulgada no espaço do museu manteve o mesmo teor de acordo com o que o mediador apresentou? Trata-se de um questionamento que diariamente divide opiniões entre intérpretes e profissionais que atuam na educação de Surdos.

Em razão das dimensões do Brasil, pode-se dizer, ainda, que a cultura surda não é estanque, por haver diversas etnias Surdas, como os ciganos e indígenas, que se diferenciam em seus costumes, religião e história, mas que por meio de suas experiências visuais, representadas pela Libras (artefato cultural linguístico) vão fortalecendo a cultura surda.

A Libras, bem como as línguas orais, apresenta variações de acordo com os grupos e/ou regiões, assim a comunidade Surda de um local pode se utilizar de sinais que em outros grupos são realizados de outra forma, dada a sua influência local, cultural, familiar, social e histórica. Esta dinâmica demonstra a riqueza da comunicação por meio da Libras e a sua capacidade de expressar sentimentos, anseios, necessidades e principalmente de constante evolução e divulgação da cultura, bem como fonte de pesquisa e produção de conhecimento.

Notamos que os museus ainda são frequentados por um público majoritariamente composto por pessoas ouvintes, neste contexto Perlin (1998, p. 56) distingue cultura surda e cultura ouvinte da seguinte maneira:

A cultura como diferença se constitui numa atividade criadora. Símbolos e práticas jamais conseguidos, jamais aproximados da cultura ouvinte. Ela é disciplinada por uma forma de ação e atuação visual. 
Já afirmei que ser surdo é pertencer a um mundo de experiência visual e não auditiva. Sugiro a afirmação positiva de que a cultura surda não se mistura a ouvinte. Isso rompe o velho status social representado para o surdo: o surdo tem de ser um ouvinte, a afirmação que é crescente, porém oculta socialmente. Rompe igualmente a afirmação de que o surdo seja um usante da cultura ouvinte. A cultura ouvinte no momento existe como constituída de signos essencialmente auditivos.

A citação acima confirma a importância dos debates acerca da cultura e ainda chama a atenção para refletirmos cada vez mais sobre como vem ocorrendo a inclusão de Surdos nos museus, espaço no qual está exposto a duas culturas (surda e ouvinte) e a infinitas possibilidades formativas que este espaço proporciona.

Há muito o Povo Surdo ${ }^{1}$ tem lutado por reconhecimento de sua língua, de seu povo, de sua comunidade e de sua cultura. Assim percebemos que, antes do reconhecimento da Libras, o acesso aos espaços externos à escola até então eram pouco ou quase nunca frequentados por eles: fatores incluíam a falta de comunicação e acessibilidade nestes espaços.

Ao pensarmos em acessibilidade para os Surdos, normalmente nos remetemos ao pensamento de que apenas a presença de um tradutor Intérprete de Libras é suficiente para sanar a incompatibilidade linguística e a sua inclusão nestes espaços. Entretanto, sabemos da importância dos recursos visuais para complementar a apreensão e compreensão do artefato exposto.

\footnotetext{
1 "Grupo de sujeitos surdos que tem costumes, história, tradições em comuns e pertencentes às mesmas peculiaridades, ou seja, constrói sua concepção de mundo através da visão, isto é, usuários defensores do que se diz ser povo surdo, o mesmo seria o grupo de sujeitos surdos que não habitam no mesmo local, mas que estão ligados por um código de formação visual in dependente[mente] do nível linguístico" (STROBEL, 2015, p. 38).
} 


\section{Língua Portuguesa (LP) no contexto dos museus}

Observa-se, então, que a LP está fortemente atrelada ao universo dos Surdos brasileiros, pois é a língua oficial de nosso país, é a língua a que o Surdo está exposto durante o período de escolarização, visto que os livros que chegam às escolas estão todos em L2 (LP é a se gunda língua para o Surdo), o acesso à comunicação (internet, redes sociais e aplicativos de mensagens instantâneas) e o uso pela sociedade ouvinte (composta, inclusive, por familiares ouvintes e pais de Surdos que não dominam a Libras), todos se dão em LP.

Nos espaços externos à escola a realidade não é diferente pois, normalmente, todas as exposições são realizadas por meio da LP ou, ainda, utilizando recursos auditivos que não condizem com a realidade dos surdos. Quando questionados sobre um dos motivos de não frequentarem o museu, os surdos listam a falta de adequações linguísticas e visuais que corroboram para a não visitação e permanência nestes espaços.

Assim como nos espaços escolares, não podemos deixar de referenciar os espaços não escolares como locais onde as informações também circulam por meio da LP e vão desde a fachada, passando pelas peças expostas e chegando à mediação realizada. Desta forma, os Surdos não se sentem linguisticamente e culturalmente incluídos nos museus.

Por outro lado, destacamos também os recursos humanos disponibilizados pelos museus, particularmente em Uberaba/MG. Parcela considerável de Surdos não consegue se comunicar fluentemente por meio da fala e da LP, sendo usuários da Libras. Neste contexto, nos questionamos para o fato de que um Surdo possa vir a passar por uma emergência ou um mal súbito dentro de um desses museus e, então, como seria realizado o atendimento inicial deste.

A situação apresentada acima, merece destaque pois, uma vez que o museu não se apresenta como espaço linguístico inclusivo, os Surdos passam a utilizá-lo apenas como lazer. Contudo, quando a visi- 
tação configura-se estritamente como lazer, as informações lá disponibilizadas tornam-se superficiais, desconexas e descontextualizadas e o conhecimento fica distorcido. Esta afirmação pode ser exemplificada baseada em relato de um estudante adolescente Surdo vinculado à nossa instituição de trabalho e que, ao ser questionado sobre os dinossauros e sua extinção na Terra, afirmou que os mesmos não estavam extintos e que apenas alguns foram "mortos por índios no ano de 2015 com bazucas". Este exemplo nos dá uma visão de como o Surdo se apropria do conhecimento sobre diversos temas de forma equivocada, por falta de comunicação realizada em sua primeira língua, a Libras (L1). E, em se tratando de museus, percebemos o quanto estes espaços são fontes riquíssimas de recursos visuais e o quanto poderiam ser mais bem exploradas para este público, possibilitando um entendimento contextualizado sobre um determinado assunto.

Os Surdos continuamente buscam por direitos de pertença a uma cultura e, ainda, buscam por tecnologias avançadas, por uma pedagogia da diferença que os respeite em sua singularidade linguística, pelo povo Surdo e a comunidade Surda. Toda essa luta objetiva a conquista de um espaço realmente inclusivo, com recursos visuais (artefatos culturais materiais) e que possam ser vistos e respeitados, não apenas "integrados" a um espaço.

Campos (2008, p. 38) identifica em sua dissertação que o "ser surdo é aquele que apreende o mundo por meio de contatos visuais, que é capaz de apropriar-se da língua de sinais e da língua escrita e de outras". Skliar (2004, p. 102) afirma a "língua de sinais anula a deficiência e permite que os Surdos consigam, então, uma comunidade linguística diferente e não um desvio da normalidade". As citações utilizadas corroboram com este estudo e demonstram para aqueles que ainda não acreditam ou desconhecem a Libras, a comunidade surda e sua cultura, o valor da Libras como forma natural de comunicação, compreensão e aprendizagem, não devendo continuar a sociedade ouvinte querendo "normalizá-los" ou, ainda, rotulá-los como incapazes, deficientes ou doentes. 
Infelizmente, esta visão, por vezes, ainda é mantida por familiares ouvintes que apresentam entes Surdos. Entretanto, com o passar dos anos, os Surdos e a comunidade surda têm demonstrado que não são deficientes, mas pessoas com experiências linguísticas e culturais diferenciadas.

Tudo isso tem contribuído para o insucesso dos Surdos e, também, servido como barreira não apenas para sua inclusão escolar, como para sua inclusão social e para a construção de sua personalidade, identidade e autonomia. Muitos Surdos, diante da superproteção familiar, chegam à idade adulta com atitudes infantilizadas ou imaturas que não correspondem ao desenvolvimento de um outro Surdo com a mesma faixa etária, mas exposto a uma educação diferenciada. Acontece que, ao serem influenciados a viverem em um espaço exclusivamente composto por ouvintes, os Surdos acabam por se anularem e, com isso, desconhecem sua língua e cultura.

A cultura surda tem sido mantida em alguns ambientes escolares compostos por estudantes Surdos destacando-se, além de sua língua, a forma como preferem registrar suas atividades, que é por meio de imagens ou filmagens, mas no contexto dos espaços não escolares a cultura surda ainda se mostra distante, predominando uma cultura ouvintista pautada na fala, audição e identificação de artefatos e outras informações em LP.

No contato, principalmente entre pares Surdos, a cultura apresenta-se como uma constante, em especial pelo fato deste Surdo estar em um ambiente linguístico no qual é possível vivenciar todos os seus artefatos por meio do uso da Libras, de modo a favorecer a constituição de sua identidade.

A cultura surda é fortalecida e multifacetada quando observamos outro artefato, que se intitula "literatura surda". A partir das experiências visuais e também da Libras, os Surdos utilizam-se de diversos gêneros, dentre eles podemos citar a história dos Surdos, as piadas, os clássicos infantis, as poesias e outros que são utilizados para registrar e divulgar sua cultura. São incontestáveis a variedade e a riqueza 
de detalhes apresentadas por meio da literatura surda. Ao observarmos as crianças contando suas experiências ou a releitura de um clássico, conseguimos penetrar um pouco mais nesse universo cultural Surdo e perceber suas peculiaridades.

Além de todos os elementos que foram citados, não se descarta a importância dos artefatos culturais materiais. Os Surdos estão a todo o tempo expostos a artefatos próprios da comunidade ouvinte: quando indagados sobre a rotina de um estudante surdo, o que se pode observar é que grande parte convive e sobrevive em um ambiente (bi)cultural, ou seja, os Surdos filhos de pais ouvintes (não fluentes em Libras) estão o tempo todo em casa expostos a uma cultura ouvinte. Ao chegarem à escola entram em contato com a Libras e com seus pares e outros estudantes e professores ouvintes, no turno vespertino (realidade em Uberaba), outros vão a uma escola específica para Surdos e têm contato com outros estudantes e professores Surdos e ouvintes e, ao final do dia, novamente retornam aos seus lares.

Nesta vertente, o intérprete não é considerado acessibilidade, por não se tratar de um recurso material ou adaptação de qualquer natureza, trata-se de um direito linguístico do surdo no ambiente em que está inserido.

Podemos citar como artefato material o Telephone Device for the Deaf (TDD), aparelho com teclado acoplado a um telefone que, a partir de uma pequena tela, é possível visualizar a mensagem que está sendo transmitida. Com o advento da internet e graças às novas tecnologias aliadas à criação de aparelhos telefônicos mais modernos, os Surdos hoje conseguem se comunicar de maneira mais rápida, eficaz, com mais privacidade e, o mais interessante, de qualquer lugar onde estiverem, a partir de aplicativos como WhatsApp e Imo (para chats e chamadas de vídeo). Tais tecnologias também têm possibilitado a comunicação a partir da língua de sinais e não apenas ficando na dependência da LP ou de um ouvinte para auxiliá-lo em uma situação de emergência, por exemplo. 
Sobre a internet, notamos que tem sido uma rica ferramenta para a divulgação da língua de sinais e para a promoção da comunidade Surda e veículo não apenas de suas batalhas, mas como meio importante para a divulgação de suas conquistas além, é claro, de servir de apoio para divulgação de eventos, pesquisas e lazer dos membros da comunidade Surda, que possuem canais, páginas e blogs. Todos são recursos que podem ser pensados para a efetiva inclusão do Surdo em museus, por exemplo.

Ressalta-se, ainda, que a internet possibilitou a muitos Surdos uma formação acadêmica, pois várias instituições possuem plataformas de ensino e a partir de suas ferramentas visuais trazem a possibilidade de pessoas surdas iniciarem ou darem continuidade aos seus estudos.

Evidencia-se, por fim, a importância de elementos visuais no processo formativo da pessoa surda, seja em ambientes escolares ou não escolares. Assim, utilizamos imagens, fotografias e registros por meio de desenhos na Educação Infantil e anos iniciais do Ensino Fundamental como ferramenta visual para que o processo de aquisição de conteúdo seja realizado respeitando a uma cultura e, principalmente, a uma língua gestual-visual. A partir destes registros os Surdos se revelam e, com as explicações aqui apresentadas, é possível notar a riqueza de detalhes e a forma como percebem o mundo à sua volta. É também por meio destes registros que a Libras circula entre a comunidade Surda, levando inúmeras histórias, fatos e conhecimento a outros Surdos e ouvintes que comungam a mesma língua.

\section{Mediadores Bilíngues - Uma formação possível?}

De acordo com a realidade mostrada em Uberaba, os Museus não possuem acessibilidade para Surdos. Apenas o Museu dos Dinossauros afirmou ter parceria com estudantes universitários que possuem em sua matriz curricular a disciplina de Libras. De acordo com essa afirmativa, primeiramente entendemos ser uma boa ação e uma 
tentativa de ao menos receber os Surdos de forma mais inclusiva em seu interior. Entretanto, é sabido que apenas participar de uma disciplina da disciplina de Libras como componente curricular no ensino superior não capacita e não habilita este estudante a atuar como "mediador" linguístico neste ambiente.

O Decreto 5626/05 aponta que a Libras deverá ser ofertada como disciplina curricular nos cursos de Magistério de nível médio, Educação Especial, Pedagogia, Letras e Fonoaudiologia, estendendo-se às demais licenciaturas. Todavia, esta disciplina fornecerá elementos basilares para a comunicação com a pessoa Surda, diferentemente da formação específica para atuar como tradutor/intérprete de Libras.

Neste contexto, entendemos que a formação continuada específica para os estudantes que possuem perfil e pretendem atuar em espaços não escolares frequentados ou que podem vir a ser frequentados por Surdos, deverá ser uma constante e este estudante deverá buscar por formação na área de tradução, aliando sempre as informações contidas no espaço com a Libras, objetivando garantir o acesso dos Surdos às informações do momento da visitação.

Ressalta-se que, mesmo estando imerso na cultura surda e participando de cursos de Libras, este mediador não se apresentará como tradutor/intérprete de Libras, uma vez que este profissional carece de formação específica por meio de curso superior de tradução e interpretação com habilitação em Libras/Língua Portuguesa, ou ainda, aprovação em bancas de proficiência realizadas por instituições vinculadas ao Ministério da Educação.

Há que se destacar a complexidade presente nos espaços externos à escola no tocante às informações que normalmente estão relacionadas às Ciências, à História e à Geografia, por exemplo. Assim, o ato de interpretar não se torna uma tarefa fácil para o profissional que pretende atuar frente a este contexto, uma vez que este deverá encontrar equivalentes linguísticos entre a língua fonte e a língua meta, ou seja, caso o surdo esteja sinalizando a língua fonte é a Libras, e quando o 
ouvinte estiver falando a língua fonte é o Português, sem prejuízos ao público que acompanha a interpretação.

Assim, se faz necessário que o tradutor-intérprete de língua de sinais e língua portuguesa deste espaço possua conhecimentos prévios sobre o local, sobre os artefatos expostos, sobre o conteúdo e, principalmente, sobre o discurso a ser realizado pelo mediador local. Desta forma, salientamos que é possível, sim, o mediador ser bilíngue, desde que se dedique e se capacite para atuar tanto com a Língua Portuguesa quanto com a Libras, além de apresentar uma trajetória formativa que contemple os conhecimentos supracitados.

Destaca-se, ainda, a necessidade de mais pesquisas voltadas para a realidade dos espaços educativos não formais que discutam a inclusão de pessoas Surdas e, principalmente, que incluam tradutoresintérpretes de língua de sinais e língua portuguesa, juntamente com professores Surdos, para se discutir questões gramaticais e estruturais que possam vir a determinar a formação de novos sinais e de, ainda, divulgar sinais em Libras já utilizados nestes espaços.

Diante de todas as dificuldades citadas, os museus, como espaços de formação e desenvolvimento cultural, devem articular-se de forma mais clara e eficiente com todos seus colaboradores, para que as devidas adaptações e adequações linguísticas, atitudinais e físicas, aconteçam de modo a receber os sujeitos Surdos. A partir deste estudo e dos contatos realizados percebe-se que atualmente na cidade de Uberaba nenhum museu apresenta as condições necessárias para a visitação da pessoa Surda, ressaltando-se a necessidade de esforços mais significativos no sentido de contratação de intérpretes e recursos tecnoló gicos para a efetiva inclusão desta comunidade nestes espaços científico-culturais.

\section{Referências}

BRASIL. Lei $\mathrm{N}^{\circ} \mathbf{1 0 . 0 9 8}$, de 19 de dezembro de 2000. Estabelece normas gerais e critérios básicos para a promoção da acessibilidade das pessoas portadores 
de deficiência ou com mobilidade reduzida. Brasília, DF, 19 dez. 2000. Disponível em: <http://portal.mec.gov.br/seesp/arquivos/pdf/lei10098.pdf.> Acesso em: 05 fev. 2019. . Ministério da Educação. Secretaria de Educação Especial. Lei No. 10.436, de 24 de abril de 2002. Dispõe sobre a Língua Brasileira de Sinais LIBRAS e dá outras providências. Disponível em: <http://www.planalto.gov.br/ccivil 03/leis/2002/L10436.htm.> Acesso em: 22 fev. 2019.

CAMPOS, M. L. I. L. Cultura surda: possível sobrevivência no campo da inclusão na escola regular? 2008. Dissertação (Mestrado em Educação) - Universidade Federal de Santa Catarina, Florianópolis, 2008.

FALK, J. H. The contribution of free-choice learning to public understanding of science. INCI [online], v. 27, n. 2, p. 62-65, feb. 2002.

FERREIRA, L. Legislação e a língua brasileira de sinais. São Paulo: Ferreira \& Bergoncci Consultoria e Publicações, 2003.

GASPAR, A. A educação formal e a educação informal em ciências. In: MASSARANI, L.; MOREIRA, I. de C.\& BRITO, F (orgs.). Ciência e público - caminhos da divulgação científica no Brasil. Rio de Janeiro: Editora da UFRJ, p. 171-183, 2002. < http://casadaciencia.ufrj.br/Publicacoes/terraincognita/cienciaepublico/livro completo.pdf.> Acesso em: 10 mar. 2019.

GESSER M.; NUERNBERG, A. H.; TONELI, M. J. F. Constituindo-se sujeito na intersecção gênero e deficiência: relato de pesquisa. Psicologia em Estudo, Maringá, v. 18, n. 3, p. 419-429, jul./set. 2013.

MARANDINO, M. Educação em museus: a mediação em foco. In: MARANDINO, M. (Orgs.). Os museus como espaços de educação não-formal. São Paulo, SP: Geenf - Grupo de Estudo e Pesquisa em Educação Não-formal e Divulgação em Ciência/ FEUSP, 2008. p. 13.

MARTINS, P. R. A inclusão social tem influência nas práticas museais? O acesso dos públicos com deficiência. MIDAS [Online], 2 | 2013. Disponível em: <http://midas.revues.org/246. $>$ Acesso em: 21 fev. 2019.

NASCIMENTO, M. V. B. Formação de Intérpretes de Libras e Língua Portuguesa. 2016. 318f. Tese (Doutorado em Linguística Aplicada e Estudos da Linguagem). Programa de Estudos Pós-Graduados em Linguística Aplicada e 
Estudos da Linguagem, Pontifícia Universidade Católica de São Paulo, São Paulo.

QUADROS, R. M. O Tradutor Intérprete de Língua de Sinais e Língua Portuguesa. Secretaria de Educação Especial, Programa Nacional de Apoio à Educação de Surdos. Brasília: MEC; SEESP, 2004.

ROCHA, S. M. O intérprete no livro de correspondências do INES de 1908. Revista Espaço, n.46, p. 247-250, 2016.

SALLES, H. M. M. L.; FAULSTICH, E.; CARVALHO, O. L. Ensino de língua portuguesa para surdos: caminhos para a prática pedagógica. Secretaria de Educação Especial; Programa Nacional de Apoio à Educação de Surdos Brasília, DF: MEC; SEESP, 2004.

SANTOS, G. B. Usos e limites da imagem da docência como profissão. Revista Brasileira de Educação, n.52, v.18, p.11-24, 2013.

SILVA, C. A. A. Entre a deficiência e a cultura: análise etnográfica de atividades missionárias com surdos. 2011. 227f. Tese (Doutorado em Ciência Social) Programa de Pós-Graduação em Antropologia Social da Faculdade de Filosofia, Letras e Ciências Humanas, Universidade de São Paulo, São Paulo.

SKLIAR, C. A Surdez, um olhar sobre as diferenças. Porto Alegre: Mediação, 2004.

PERLIN, G. T. T. Identidade Surda. In: SKLIAR, C. (Org.). A Surdez: um Olhar Sobre as Diferenças. Porto Alegre: Mediação, 1998, p. 51- 72.

STROBEL, K. As imagens do outro sobre a cultura surda. 3. ed. rev. Florianópolis: Ed. da UFSC, 2015. 148 p.

ZOVICO, N. A; SILVA, C. A. A. Acessibilidade a serviços públicos: direito de igualdade. In: ALBRES, N.A.; NEVES, S.L.G. (Orgs.) Libras em estudo: política linguística. São Paulo: FENEIS, 2013. 169p. 